\title{
The Importance of Physical Activity in the Interaction of Motor and Cognitive Functions in Elderly People
}

\author{
Vida Janina Česnaitienè ${ }^{1}$, Zbigniew Ossowski ${ }^{2}$, Diana Karanauskienè ${ }^{1}$, \\ Gabrielė Auškalnyte் ${ }^{1}$, Ema Grigẻnaitytė ${ }^{1}$, Gintarė Katkute் ${ }^{1}$, \\ Samrat Sheoran $^{1}$, Vaidas Mickevičius ${ }^{3}$ \\ Lithuanian Sports University', Kaunas, Lithuania \\ Gdansk Sports University², Gdansk, Poland \\ University of Applied Engineering Sciences ${ }^{3}$, Kaunas, Lithuania
}

\begin{abstract}
Background. It is predicted that in 2060, the number of elderly people in Lithuania (62 and over years of age) will be $31.2 \%$ (Tamutiene \& Naujanienè, 2013). The maintenance of stable posture requires particular attention because it gets more difficult to sustain it while doing multiple moves at the same time when you are getting older (Woo, Davids, Liukkonen, Chow, \& Jaakkola, 2017). The aim of the study was to determine the importance of physical activity for the interplay of motor and cognitive functions in elderly people.

Methods. Evaluation of static equilibrium by posturographic method, evaluation of cognitive functions, statistical analysis.

Results. The results of the physically active and inactive research subjects were statistically significant $(p=.043)$ in memory task with the eyes closed and in a simple position. A statistically significant difference in the sway velocity (Vsc) between the physical activity groups with eyes closed in simple position was also observed $(p=.044)$. Double task with eyes closed resulted in worse balance performance.

Conclusions. 1. Physical activity did not affect the motor function of the elderly. There were no differences between the physically active and inactive subjects in the assessed behavioral indices. 2. Physical activity did not affect the cognitive functions of the elderly. All elderly subjects were equally mistaken in their cognitive memory task. 3. The motor functions of the physically active elderly are controlled statistically significantly better when performing additional cognitive tasks than those of the physically inactive ones.
\end{abstract}

Keywords: balance, elderly, physical activity.

\section{INTRODUCTION}

I

$\mathrm{n}$ the modern world, one of the most pressing topics is increasing life expectancy and the aging society. As people get older, they become less physically active, which often leads to loss of function and weakness, as well as the need for home care services (Burton et al., 2019). In Lithuania, there are $40.5 \%$ of adults who engage in physical activity for at least 30 minutes 5 days a week or more (Liuima \& Valentiene, 2018). The physical activity of the majority of Lithuanian adults does not reach the recommendations of the World Health Organization
(2010). Low physical activity leads to faster muscle loss in old age, leading to imbalance and increased risk of falls. Impaired cognitive function is also associated with a higher risk of falls (Woo et al., 2017). The risk of falling is greatly increased when two tasks are performed at the same time, such as: walking and using the phone, thinking, speaking, calculating and walking, trying to stay stable (Woo et al., 2017). Increased cognitive function during a dual task requires compensatory mechanisms to maintain a stable body position (Seidler et al., 2010). 
Research confirms the benefits of physical activity in preventing falls, such as combining strength and balance training with specific cognitive training has a positive effect on walking, gait, and attention span, improves performance, and reduces the risk of falls (Van Het Reve \& de Bruin, 2014). The main problem questions of this study were to assess whether individuals with higher levels of physical activity, regardless of the nature of the training, will have better balance and cognitive function, or will be able to manage balance more effectively by performing a cognitive task. The aim of the study was to determine the significance of physical activity in elderly people for the interaction of motor and cognitive functions.

\section{METHODS}

Subjects. The study included 53 subjects. Criteria for inclusion of subjects: during the last 6 months no intense physical exertion, not taking medications that could affect test results, no diagnosed cardiovascular system or neuromuscular disorders that could limit exercising. The characteristics of the subjects are presented in Table 1.

Table 1. Characteristics of research participants

\begin{tabular}{|c|c|c|}
\hline \multirow{2}{*}{ Gender } & Male & 6 \\
\hline & Female & 47 \\
\hline Age & \multicolumn{2}{|l|}{$70.22 \pm 6.27$} \\
\hline BMI $\left(\mathrm{kg} / \mathrm{m}^{2}\right)$ & \multicolumn{2}{|l|}{$26.91 \pm 3.364$} \\
\hline \multirow{2}{*}{ Physical activity group } & Physically inactive & 14 \\
\hline & Physically active & 30 \\
\hline
\end{tabular}

Note. Mean \pm standard deviation.

Instruments. The physical activity of the elderly was assessed according to the time physically active during the week. Subjects who were physically active for 150 minutes or more per week were assigned to the physically active group, and those who were physically active for less than 150 minutes per week - to the physically inactive group. We divided the subjects into groups according to physical activity based on WHO recommendations.

For the evaluation of the motor system, we chose the analysis of balance behaviour of the subjects. During the study, static posturography was performed using a force plate and computer software to record the signals (KISTLER, Switzerland, Slimline System 9286). During the study, the subject stood on the force plate in two different poses:

1) Simple posture with legs clenched, eyes open, arms crossed on chest;

2) Simple posture with clenched legs, eyes closed, arms crossed on chest.

In the balance assessment, all subjects were asked to stand on a Kistler force plate in the middle with their arms crossed on their chests (Figure). The subject's gaze was directed to one point directly in front of themselves. The duration of posturogram recording was $25 \mathrm{~s}$. Of these, $20 \mathrm{~s}$ interval was selected for data analysis. The first $5 \mathrm{sec}$. were designed for adaptation to posture. Discretization of the recorded signal was $10 \mathrm{~ms}$, i.e. power plate signals were recorded at $100 \mathrm{~Hz}$. The pressure center (PC) was the starting point of the vertical component vector of the support reaction force, the coordinate change curve. The following balance parameters were analysed: $\mathrm{dx}-\mathrm{PC}$ the rate of change of the coordinates in the lateral (ML) direction $(\mathrm{mm} / \mathrm{s})$; dy - PC the rate of change of the coordinates in the forward-backward (AP) direction $(\mathrm{mm} / \mathrm{s})$; Vcop - total rate of change of coordinates $(\mathrm{mm} / \mathrm{s})$.

Balance instability and the distribution of attention to motor control were assessed during the dual task by measuring the velocity of balance fluctuation (Vcop). The dual task effect (DTE) reflects the effect of an additional task on a person performing an action under dual task conditions. The effect of a dual task was expressed as a percentage compared to the performance of a single task using a formula: DTE [(dual task result - single task result)/dual task result]*100. Positive percentage of DTE balance indicates increased instability (higher Vcop). Positive percentage of the DTE cognitive function reflects a decrease in accuracy. i.e. increase in errors (Doumas, Smolders, \& Krampe, 2008).

A dual task was performed to assess the interaction of motor-cognitive functions. Motor task was balance control, cognitive tasks were word repetition test and mathematical processing test. Cognitive tasks were the same for all subjects, but they were arranged in a random order during the study. A dual task was performed to simultaneously assess subjects' balance control and cognitive function. Subjects were asked to perform two competitive tasks simultaneously - to maintain 
Note. a) simple position with eyes open; b) simple position with eyes closed.

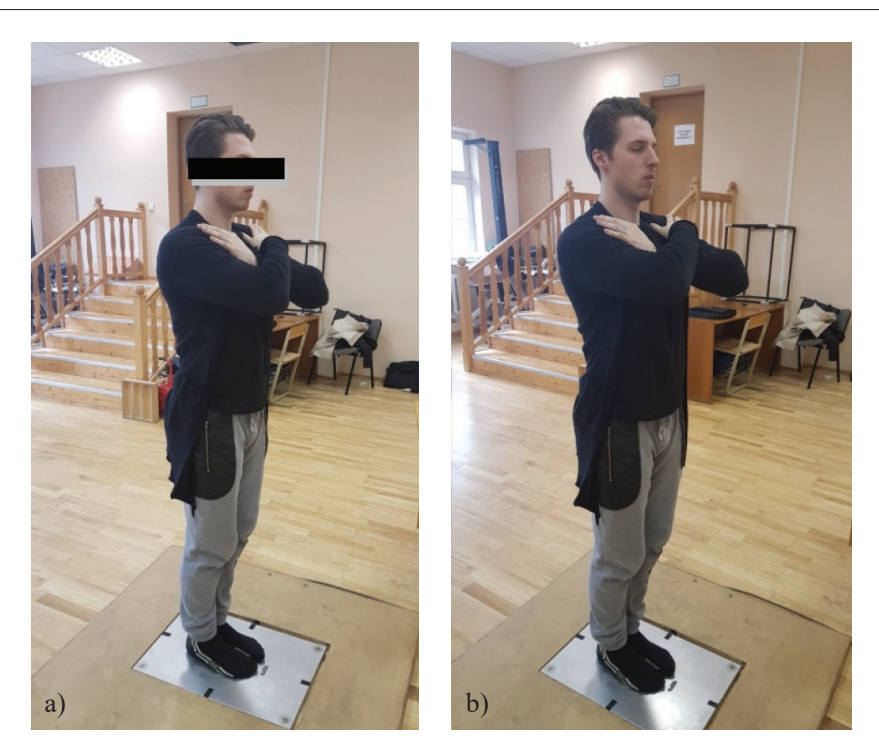

balance and perform a cognitive task correctly at the same time.

Memory was assessed using a 10 -word repetition test. The test is designed to assess the amount of memory. The subject was asked to memorize and repeat as many words as possible. During the study, an audio recording was played, where 10 nouns were listed within $20 \mathrm{~s}$ (1 word/2 s). During the dual task, the subject had to stand on the Kistler platform, focusing on the cognitive task and repeating the memorized words at the end of the audio recording. The number of words remembered was estimated.

The calculation task consisted of a sequence of subtraction and addition arithmetic operations that lasted $20 \mathrm{~s}$. The numbers were given to the subjects during the balance assessment, for example " $7+3-2+3+3$...". During the dual task, the subject had to stand on the Kistler platform, focusing on the cognitive task (performing arithmetic operations on the mind) and saying the answer at the end of the task. The same calculation tasks were used for all subjects.

Data analysis. The research data were processed using computer programs SPSS 20.0 and Microsoft Office Excel (2010). Arithmetic means, standard deviations, and correlation coefficients were calculated. Student's t criterion for independent samples was used to compare the results of the tasks. Pearson's correlation coefficient was used to assess the strength of the relationship. Nonparametric tests were used to verify data that did not meet the requirements of analysis of variance.

\section{RESULTS}

Relationship between physical activity and motor functions in the elderly. Table 2 shows a comparison of the results of the dual task in the physically active and inactive study groups. During the memory task, the results of physically active and inactive study groups differed statistically significantly, $p<.05$. A statistically significant difference in the velocity of fluctuation (Vsc) was also observed between the groups of physical activity with the eyes closed in the simple position during the calculation task, $p<.05$. Dual task with closed eyes resulted in poorer balance scores. Balance indicator was the velocity of fluctuation of the projection of the pressure centre in the horizontal plane (Vsc).

Relationship between physical activity and cognitive functions in the elderly. According to the results of the study, the cognitive functions of the subjects without the task and during the double task did not differ statistically significantly, $p>.05$. The means and standard deviations of the results of physically active and inactive groups were quite similar (Table 3). To further evaluate the relationship between physical activity and cognitive functions, we used only errors in cognitive word memory tasks.

We found that physical activity had no effect on cognitive functions in the elderly. All subjects, despite their physical activity, were equally mistaken in performing cognitive tasks. 
Vida Janina Česnaitienè, Zbigniew Ossowski, Diana Karanauskienè, Gabrielè Auškalnytè, Ema Grigènaitytè, Gintarè Katkutè, Samrat Sheoran, Vaidas Mickevičius THE IMPORTANCE OF PHYSICAL ACTIVITY IN THE INTERACTION OF MOTOR AND COGNITIVE FUNCTIONS IN ELDERLY PEOPLE

Table 2. Dual task effect on motor functions insubjects in the aspect of their physical activity
Note. ${ }^{*} p<.05 ;$ PAU/PAA clenched legs legs closed eyes/ clenched legs legs open eyes; PAU_A/PAA_A - clenched legs legs closed eyes with the memory task/clenched legs legs open eyes with thememory task; PAU S/PAA S - clenched legs legs closed eyes with mathematical processing task/clenched legs legs open eyes with mathematical processing task. Vsc - balance index.

Table 3. Dual task effect on $\operatorname{cog}$ nitive functions in subjects in the aspect of their physical activity

Note. * $p>.05$; PA - simple posture; PAU A/ PAA A - clenched legs legs closed eyes with the memory task/clenched legs legs open eyes with thememory task.

Table 4. Correlation between physical activity, posture and errors

Note. Correlation coefficient $(r) \mid \mathrm{val}-$ ues: *0-.3 weak correlation; **.3-.7 average correlation; **.7-1 strong correlation. PA - physical activity; PAA/PAU - simple posture with eyes open/closed; Errors - number of errors; PAU_S/PAA/S - simple posture with eyes open/closed with a mathematical processing task; PAU A/ PAA A - simple posture with eyes open/closed with a memory task.

\begin{tabular}{|c|c|c|c|}
\hline Task & Physical activity group & $\begin{array}{c}\text { Vsc }(\mathrm{mm} / \mathrm{s}) \\
\text { Mean } \pm \text { Standard } \\
\text { deviation }\end{array}$ & $p$ \\
\hline \multirow{2}{*}{ PAU } & Physically inactive & $29.34 \pm 13.77$ & \multirow{2}{*}{.086} \\
\hline & Physically active & $23.62 \pm 7.87$ & \\
\hline \multirow{2}{*}{ PAA } & Physically inactive & $16.49 \pm 6.57$ & \multirow[t]{2}{*}{.206} \\
\hline & Physically active & $14.48 \pm 3.57$ & \\
\hline \multirow{2}{*}{ PAU_A } & Physically inactive & $29.81 \pm 12.15$ & \multirow[t]{2}{*}{.043} \\
\hline & Physically active & $22.93 \pm 9.06$ & \\
\hline \multirow{2}{*}{ PAA_A } & Physically inactive & $18.19 \pm 6.80$ & \multirow{2}{*}{.519} \\
\hline & Physically active & $16.69 \pm 7.27$ & \\
\hline \multirow{2}{*}{ PAU_S } & Physically inactive & $28.66 \pm 11.55$ & \multirow[t]{2}{*}{.044} \\
\hline & Physically active & $22.22 \pm 8.56$ & \\
\hline \multirow{2}{*}{ PAA_S } & Physically inactive & $18.01 \pm 7.05$ & \multirow[t]{2}{*}{.812} \\
\hline & Physically active & $17.41 \pm 7.96$ & \\
\hline
\end{tabular}

\begin{tabular}{|c|c|c|c|}
\hline Tasks & Physical activity group & Errors $(M \pm S D)$ & $p$ \\
\hline \multirow{2}{*}{ PA } & Physically inactive & $4.09 \pm 1.25$ & \multirow{2}{*}{.897} \\
\hline & Physically active & $4.13 \pm 0.96$ & \\
\hline \multirow{2}{*}{ PAU_A } & Physically inactive & $4.31 \pm 1.10$ & \multirow{2}{*}{.325} \\
\hline & Physically active & $4.01 \pm 0.82$ & \\
\hline PAA_A & Physically inactive & $3.82 \pm 1.30$ & .566 \\
\hline
\end{tabular}

\begin{tabular}{|l|c|c|c|c|}
\hline \multirow{2}{*}{ Task } & \multicolumn{2}{|c|}{ PA } & \multicolumn{2}{c|}{ PAA } \\
\cline { 2 - 5 } & $\boldsymbol{r}$ & $\boldsymbol{p}$ & $\boldsymbol{r}$ & $\boldsymbol{p}$ \\
\hline PAU & -.271 & .075 & $\mathbf{. 7 2 6}^{\text {** }}$ & .000 \\
\hline PAU_A & $-.363^{*}$ & .017 & $\mathbf{. 5 9 2}^{\text {** }}$ & .000 \\
\hline PAA_A & -.167 & .277 & $\mathbf{. 5 7 4}^{\text {** }}$ & .000 \\
\hline PAU_S & -.282 & .064 & $\mathbf{. 6 9 9}^{\text {** }}$ & .000 \\
\hline PAA_S & -.032 & .834 & $\mathbf{. 5 4 7}^{\text {** }}$ & .000 \\
\hline Erors_PAU_A & -.172 & .265 & $\mathbf{. 4 6 3}^{\text {** }}$ & .001 \\
\hline Erors_PAA_A & -.149 & .333 & $\mathbf{. 5 6 7}^{\text {** }}$ & .000 \\
\hline
\end{tabular}

Significance of physical activity in elderly people for the interaction of their motor and cognitive functions. In order to reveal the significance of physical activity in older people for the interaction of motor and cognitive functions, a correlation was performed between physical activity, dual and simple task performance, and errors. The worse a person's balance (Vsc), the less correct answers they give. Simple posture with eyes open correlates with the number of errors with eyes closed and eyes open in a simple posture during a cognitive memory task. Physical activity correlates with simple posture with eyes closed performing a cognitive memory task. 


\section{DISCUSSION}

The results of this study showed that the balance of physically active older people with the eyes closed was statistically significantly more stable than that of physically inactive people. The velocity of balance fluctuations with open and closed eyes during the memory or mathematical processing tasks deteriorated, while the number of cognitive task errors increased. Subjects tried to concentrate on cognitive memory and computational tasks, leading to poorer balance. Studies show that when motor and cognitive tasks are performed simultaneously, the cognitive task has a negative effect on the balance of the human body, especially in the elderly (Fraser, DeMont, \& Penhune, 2007). Fear of falling is related to the limitation of a person's activities, as well as to poorer physical and cognitive functions and has a negative impact on the quality of life (Schoene et al., 2019).

The results of the study revealed a relationship between the balance behaviour and the amount of cognitive task errors in a dual task. The more unstable the balance (the higher the value of Vsc), the more errors in the cognitive task. Vsc results correlate with the number of errors in the cognitive task for memory with eyes closed and open. In most cases, an elevated Vsc is a sign of poor balance control. However, elderly people often consciously improve their balance control by focusing more on balance management (Resch, May, Tomporowski, \& Ferrara, 2011; Ruffieux, Keller, Lauber, \& Taube,
2015) instead of automatic balance adjustment, which reduces ankle proprioceptic control (Boisgontier et al., 2014). A study conducted by Latvian researchers in 2019 (Šneidere et al., 2019) aimed to investigate the relationship between motor and cognitive functions of lifelong physically active older people. Seniors who had a longer experience of physical activity showed better results, but no significant differences were found between physically active and inactive seniors and their cognitive and motor indicators. Also, no significant differences between physically active and inactive people were found in the study of other researchers in 2016 (Young, Dowell, Watt, Tabet, \& Rusted, 2016).

\section{CONCLUSIONS}

1. Physical activity did not affect the motor function in the elderly. There were no differences between the physically active and inactive subjects in the assessed behavioural indices.

2. Physical activity did not affect the cognitive functions in the elderly. All elderly subjects were equally mistaken in their cognitive memory task.

3. The motor functions of the physically active elderly people are controlled statistically significantly better when performing additional cognitive tasks than those of the physically inactive elderly people.

\section{REFERENCES}

Boisgontier, M. P., Van Halewyck, F., Corporaal, S. H., Willacker, L., Van Den Bergh, V., Beets, I. A., Levin, O., \& Swinnen, S. P. (2014). Vision of the active limb impairs bimanual motor tracking in young and older adults. Frontiers in Aging Neuroscience, 6, 320. doi: 10.3389/fnagi.2014.00320.

Burton, E., Farrier, K., Galvin, R., Johnson, S., Horgan, N. F., Warters, A., \& Hill, K. D. (2019). Physical activity programs for older people in the community receiving home care services: systematic review and meta-analysis. Clinical Interventions in Aging, 14, 1045. doi: 10.2147/CIA.S205019

Doumas, M., Smolders, C., \& Krampe, R. T. (2008). Task prioritization in aging: effects of sensory information on concurrent posture and memory performance. Experimental Brain Research, 187(2), 275-281. doi: 10.1007/s00221-008-1302-3

Fraser, S. A., Li, K. Z., DeMont, R. G., \& Penhune, V. B. (2007). Effects of balance status and age on muscle activation while walking under divided attention. The Journals of Gerontology Series B: Psychological Sciences and Social Sciences, 62(3), P171-P178. doi. org/10.1093/geronb/62.3.P171

Liuima, V., \& Valentienè, J. (2018). Suaugusiuju gyvensenos tyrimas: $2018 \mathrm{~m}$. rodikliu suvestiné-ataskaita. Vilnius: Higienos instituto visuomenès sveikatos technologijų centro visuomenès sveikatos tyrimų skyrius.

Resch, J. E., May, B., Tomporowski, P. D., \& Ferrara, M. S. (2011). Balance performance with a cognitive task: A continuation of the dual-task testing paradigm. Journal of Athletic Training, 46(2), 170-175. doi: 10.4085/10626050-46.2.170

Ruffieux, J., Keller, M., Lauber, B., \& Taube, W. (2015). Changes in standing and walking performance under dual-task conditions across the lifespan. Sports Medicine, 45(12), 1739-1758. doi: 10.1007/s40279-015-0369-9.

Schoene, D., Heller, C., Aung, Y. N., Sieber, C. C., Kemmler, W., \& Freiberger, E. (2019). A systematic 
review on the influence of fear of falling on quality of life in older people: Is there a role for falls? Clinical Interventions in Aging, 14, 701. doi: 10.2147/CIA. S197857

Seidler, R. D., Bernard, J. A., Burutolu, T. B., Fling, B. W., Gordon, M. T., Gwin, J. T. \& Lipps, D. B. (2010). Motor control and aging: Links to age-related brain structural, functional, and biochemical effects. Neuroscience Biobehavioral Review, 34(5), 721-733. doi.org/10.1016/j.neubiorev.2009.10.005

Šneidere, K., Alruwais, N., Dowell, N. G., Arnis, V., Harlamova, J., Kupčs, K., ... \& Rusted, J. (2019). Differences in long-and short-term memory performance and brain matter integrity in seniors with different physical activity experience. Proceedings of the Latvian Academy of Sciences. Section B. Natural, Exact, and Applied Sciences, 73(2), 158-163. doi.org/10.2478/prolas-2019-0025

Tamutienè, I., \& Naujanienè, R. (2014). Senyvo amžiaus asmenu socialiniu paslaugu prieinamumo namuose patirtys. Tiltai, 65(4), 63-78.
Van Het Reve, E., \& de Bruin, E. D. (2014). Strengthbalance supplemented with computerized cognitive training to improve dual task gait and divided attention in older adults: A multicenter randomized-controlled trial. BMC Geriatrics, 14(1), 134. doi: 10.1186/14712318-14-134

Woo, M. T., Davids, K., Liukkonen, J., Chow, J. Y., \& Jaakkola, T. (2017). Falls, cognitive function, and balance profiles of Singapore community-dwelling elderly Individuals: Key risk factors. Geriatric Orthopaedic Surgery \& Rehabilitation, 8(4), 256-262. doi: $10.1177 / 2151458517745989$

World Health Organization. (2010). Global recommendations on physical activity for health. World Health Organization.

Young, J. C., Dowell, N. G., Watt, P. W., Tabet, N., \& Rusted, J. M. (2016). Long-term high-effort endurance exercise in older adults: Diminishing returns for cognitive and brain aging. Journal of Aging and Physical Activity, 24(4), 659-675. doi:10.1123/japa.2015-0039 